\title{
Review
}

\section{Aquatherapy for Neurodegenerative Disorders}

\author{
Alyson R. Plecash and Blair R. Leavitt* \\ Centre for Huntington Disease, UBC Hospital and The Centre for Molecular Medicine and Therapeutics and \\ Department of Medical Genetics, Child and Family Research Institute, University of British Columbia, Vancouver, \\ BC, Canada
}

\begin{abstract}
Aquatherapy is used for rehabilitation and exercise; water provides a challenging, yet safe exercise environment for many special populations. We have reviewed the use of aquatherapy programs in four neurodegenerative disorders: Parkinson's disease, multiple sclerosis, amyotrophic lateral sclerosis, and Huntington's disease. Results support the use of aquatherapy in Parkinson's disease and multiple sclerosis, however further evidence is required to make specific recommendations in all of the aforementioned disorders.
\end{abstract}

Keywords: Chorea, Huntington('s) disease, Huntington, Huntington chorea, Parkinson('s) disease, Parkinson, Multiple sclerosis, Amyotrophic lateral sclerosis, Lou Gehrig's disease, hydrotherapy, aquatherapy, aquatic therapy, pool therapy

\section{INTRODUCTION}

Aquatherapy - also known as aquatic therapy, hydrotherapy, or pool exercise - is used in many exercise programs and with a variety of populations. Several types of water-based therapy have been used for the purpose of rehabilitation and treatment of chronic illness since the early 1900s [1]. Water acts as a unique medium allowing for weight-bearing exercise without stressing the joints, movement and stability drills without the fear of falling, and multi-directional resistance training without the need for free weights or bands. Aquatherapy, for general rehabilitation purposes and special populations, is commonly performed in a warm (above $30^{\circ} \mathrm{C}$ ), shallow (chest-deep) pool and may involve a variety of exercise modalities including aerobic, stretching/range of motion (ROM), resistance, and stability training [2]. Aquatherapy generally includes a warm-up, an exercise base (including

*Correspondence to: Blair R. Leavitt, Centre for Molecular Medicine and Therapeutics, 950 West 28th Avenue, Room 2020, Vancouver, BC, V5Z4H4, Canada. Tel.: +1 604875 3801; Fax: +1 604875 3840; E-mail: bleavitt@cmmt.ubc.ca. both aerobic and resistance type exercises), and a cooldown. Exercises are tailored to an individual's ability, however kicking and walking drills are commonly used for aerobic and movement pattern training, while resistive movements (anything involving pushing, pulling, or bending) against water are used for strength training of the limbs and postural muscles.

The benefit of performing weight-bearing exercise without stressing the joints has been utilized in waterbased programs for special populations including the frail elderly and those with osteoarthritis (OA) [2-5]. Aquatherapy has been shown to reduce pain and improve function in those with lower limb osteoarthritis in short-term studies [2]. A pool therapy program offers special populations the opportunity to complete movement tasks in the water that are no longer feasible on land [2].

In the frail elderly, weekly aquatherapy has shown improvements in health-related quality of life (HRQL) and mobility-related activities of daily living (ADL) $[3,4]$. Although exercise boasts benefits for both one's physical and mental health, the fear of falling is a real barrier to participation in exercise programs, especially 
for populations at risk. Through exercising in water, this risk was reduced or alleviated in the frail elderly [3, 4]. This benefit would extend into many neurological conditions, because falling, as a result of movement disturbance or postural instability is a real fear in these populations [3].

The natural resistance water provides can be utilized in multi-directional strengthening exercises. Waterbased exercise programs used for stroke rehabilitation have shown more strength gains compared to landbased exercise programs, however these results have not been shown in all populations $[6,7]$. The natural environment of a pool, allowing for enough resistance to promote strengthening, while simultaneously helping to prevent injury through controlling movement direction and velocity, may be beneficial for patients with neurodegenerative conditions.

\section{THE USE OF EXERCISE THERAPY IN NEURODEGENERATIVE DISORDERS}

Huntington's disease (HD) is a predominantly adult-onset neurodegenerative disease with autosomal dominant inheritance, manifested symptomatically by progressive motor dysfunction, cognitive impairment and psychiatric changes [8-10]. The motor dysfunction in HD consists of both disordered and poorly coordinated voluntary motor function, and involuntary movements [11]. Chorea is the predominant involuntary movement, although tics and dystonia can also be present $[10,11]$. Generally, physiotherapy guidelines have focussed on exercise therapy to maintain, correct, and coordinate voluntary movements for as long as possible in those with HD [10]. The literature suggests that exercise therapy may benefit voluntary gross motor movements, such as walking; it is suggested that physiotherapy is beneficial for those with HD to train and maintain the ability to perform ADLs [10]. It has also been suggested that aquatherapy may reduce chorea during and for a time following the exercise session [12]. Recent studies in mouse models of HD support the use of exercise therapy in HD. One study demonstrated that mice exposed to exercise (wheel running) at a young age had delayed motor-impairment, compared to mice not exposed to exercise [13]. Another study found that exercise slowed cognitive decline in an HD mouse model [14].

Exercise therapy in Parkinson's disease (PD) has primarily targeted slowing of motor progression. Exercise programs improve motor symptoms (such as bradykinesia and tremor) in PD $[15,16]$. Studies in Multiple sclerosis (MS) have shown exercise to be effective at improving physical health, in particular muscular strength and walking gait, as well as emotional health, in particular by fatigue reduction $[17,18]$. Studies in amyotrophic lateral sclerosis (ALS) have been conducted looking at the effects of exercise on the progressive focal muscle weakness of ALS; they have showed positive results especially when stretching, strengthening, and aerobic exercises have been used [19]. Stretching has been shown to prevent contractures for longer, strengthening has been shown to improve function and quality of life, and aerobic exercise seems to be safe at both early and late stage disease and may improve respiratory function [19].

\section{AQUATHERAPY IN NEURODEGENERATIVE DISEASE}

A systematic survey of the literature identified 31 studies that assessed the use of aquatherapy/hydrotherapy as treatment in one of four neurological conditions: HD, PD, MS, and ALS (Tables 1 and 2) [20-52]. Two randomized clinical trials (RCTs) explored the use of aquatherapy in PD [22, 23]. Comparison of land-based versus water-based exercise programs was performed by Vivas et al. [22] and data regarding postural stability and self-movement were collected through five functional assessments: the Functional Reach Test, the Berg Balance Scale, the UPDRS (Unified Parkinson's Disease Rating Scale), the 5-meter walk test, and the Timed Up and Go test. Both interventions significantly improved performance on the Functional Reach Test, but only the aquatic therapy intervention significantly improved performance on the Berg Balance Scale and the UPDRS. Ayan and Cancela [23] studied the efficacy of water exercise programs of different intensities. The low-intensity program consisted of warm-up, balance, dynamic, and cool-down exercises, while the muscular resistance program consisted of warm-up, muscular resistance, and cool-down exercises. They found improvements in quality of life (QOL) in both groups, but significant improvement in functional mobility and Parkinsonian motor symptoms in the muscular resistance group only. Giladi discussed the use of an underwater treadmill, to help train gait patterns in an expert review paper [24]. Crizzle and Newhouse used a focus group to discuss motivators for exercise adherence in PD with aquatherapy program participants and their caregivers [25]. Results showed that exercise program leaders were important in encouraging participation; their 
Table 1

Characteristics of included studies

\begin{tabular}{|c|c|c|c|c|c|c|c|c|c|}
\hline \multirow{2}{*}{ Study } & \multirow[b]{2}{*}{$\begin{array}{l}\text { Disease } \\
\text { Studied }\end{array}$} & \multirow[b]{2}{*}{$\begin{array}{l}\text { Level of } \\
\text { Evidence }\end{array}$} & \multirow[b]{2}{*}{$\begin{array}{l}\text { Number of } \\
\text { Participants }\end{array}$} & \multicolumn{3}{|c|}{ Intervention Type } & \multicolumn{3}{|c|}{ Intervention Details } \\
\hline & & & & $\begin{array}{c}\text { Water } \\
\text { exercise } \\
\text { only }\end{array}$ & $\begin{array}{l}\text { Water } \\
\text { vs. land }\end{array}$ & Other & $\begin{array}{c}\text { Intervention } \\
\text { length } \\
\text { (weeks) }\end{array}$ & $\begin{array}{c}\text { Number of } \\
\text { sessions } \\
\text { (per week) }\end{array}$ & $\begin{array}{c}\text { Length of } \\
\text { sessions } \\
\text { (minutes) }\end{array}$ \\
\hline Vivas et al. [23] & PD & II & 11 & & $\bullet$ & & 4 & 2 & 45 \\
\hline Ayan and Cancela [24] & PD & III & 21 & $\bullet$ & & & 12 & 2 & 60 \\
\hline Giladi [25] & PD & VI & / & & & $\bullet$ & $n / a$ & $n / a$ & $n / a$ \\
\hline Crizzle and Newhouse [26] & PD & 1 & 4 & $\bullet$ & & & 6 & 3 & $20-60$ \\
\hline Mori et al. [27] & MS & II & 30 & & $\bullet$ & & 2 & 5 & 120 \\
\hline Castro-Sanchez et al. [28] & MS & II & 73 & & $\bullet$ & & 20 & 2 & 60 \\
\hline Kargarfard et al. [29] & MS & II & 32 & $\bullet$ & & & 8 & 3 & 60 \\
\hline Bansi et al. [30] & MS & II & 60 & & $\bullet$ & & 3 & 5 & 30 \\
\hline Salem et al. [31] & MS & IV & 11 & $\bullet$ & & & 5 & 2 & 60 \\
\hline Coco et al. [32] & MS & IV & 1 & $\bullet$ & & & 15 & $?$ & 60 \\
\hline Gehlsen et al. [33] & MS & IV & 9 & - & & & 10 & 3 & 60 \\
\hline Correia de Sa et al. [34] & MS & VI & / & $\bullet$ & & & $\mathrm{n} / \mathrm{a}$ & $\mathrm{n} / \mathrm{a}$ & $\mathrm{n} / \mathrm{a}$ \\
\hline Beer et al. [35] & MS & $\mathrm{VI}$ & l & - & & & $\mathrm{n} / \mathrm{a}$ & $\mathrm{n} / \mathrm{a}$ & $\mathrm{n} / \mathrm{a}$ \\
\hline Peterson \& Bell [36] & MS & VI & / & - & & & $\begin{array}{c}10 \text { wks - } 3.5 \\
y r s\end{array}$ & $\mathrm{n} / \mathrm{a}$ & $\mathrm{n} / \mathrm{a}$ \\
\hline Woods [37] & MS & VI & 2 & $\bullet$ & & & $\mathrm{n} / \mathrm{a}$ & $n / a$ & $\mathrm{n} / \mathrm{a}$ \\
\hline Pappalardo et al. [38] & MS & $\mathrm{VI}$ & / & $\bullet$ & & & $\mathrm{n} / \mathrm{a}$ & $n / a$ & $\mathrm{n} / \mathrm{a}$ \\
\hline Henze et al. [39] & MS & $\mathrm{VI}$ & I & - & & & $n / a$ & $\mathrm{n} / \mathrm{a}$ & $n / a$ \\
\hline Peterson [40] & MS & 1 & 1 & & & $\bullet$ & 7 & 2 & 45 \\
\hline Broach and Dattilo [41] & MS & 1 & 4 & - & & & $?$ & 3 & 45 \\
\hline Broach and Dattilo [42] & MS & 1 & 4 & $\bullet$ & & & $?$ & 3 & 45 \\
\hline Broach et al. [43] & MS & 1 & 4 & $\bullet$ & & & $?$ & 3 & 45 \\
\hline Apel et al. [44] & MS & 1 & 254 & & & $\bullet$ & $\mathrm{n} / \mathrm{a}$ & $n / a$ & $\mathrm{n} / \mathrm{a}$ \\
\hline Apel et al. [45] & MS & 1 & 154 & & & $\bullet$ & $\mathrm{n} / \mathrm{a}$ & $\mathrm{n} / \mathrm{a}$ & $\mathrm{n} / \mathrm{a}$ \\
\hline Fawcett et al. [46] & MS & 1 & 16 & & & $\bullet$ & $\mathrm{n} / \mathrm{a}$ & $\mathrm{n} / \mathrm{a}$ & $\mathrm{n} / \mathrm{a}$ \\
\hline Lewis [47] & MS & 3 & I & $\bullet$ & & & ongoing & $2-3$ & 60 \\
\hline O'Connell [48] & MS & 3 & I & $\bullet$ & & & $\mathrm{n} / \mathrm{a}$ & $\mathrm{n} / \mathrm{a}$ & $\mathrm{n} / \mathrm{a}$ \\
\hline Veenstra et al. [49] & MS & 3 & 53 & $\bullet$ & & & Variable & Variable & Variable \\
\hline Andersen et al. [50] & ALS & 1 & I & $\bullet$ & & & $\mathrm{n} / \mathrm{a}$ & $\mathrm{n} / \mathrm{a}$ & $\mathrm{n} / \mathrm{a}$ \\
\hline Bedlack and Aggarwal [51] & ALS & $\mathrm{VI}$ & I & $\bullet$ & & & $\mathrm{n} / \mathrm{a}$ & $\mathrm{n} / \mathrm{a}$ & $\mathrm{n} / \mathrm{a}$ \\
\hline Johnson [52] & ALS & 4 & 1 & $\bullet$ & & & $?$ & 1 & 45 \\
\hline Sheaff [18] & HD & $\mathrm{VI}$ & 1 & $\bullet$ & & & $?$ & 1 & $?$ \\
\hline
\end{tabular}

This review includes literature published between 1946 and July 30th 2013 from databases: Medline (1946 - July 2013), Cochrane Central Register of Controlled Trials (1991 - June 2013), Cochrane Database of Systematic Reviews (2005 - May 2013), Embase (1974 - July 2013), and CINHAL (1982 - present). Search terms of study sample include: chorea, Huntington('s) disease, Huntington, Huntington chorea, Parkinson('s) disease, Parkinson, Multiple sclerosis, Amyotrophic lateral sclerosis and Lou Gehrig's disease. Search terms of intervention types include: hydrotherapy, aquatherapy, aquatic therapy, and pool therapy. Grey background in Table 1 indicates an RCT. Quantitative articles were ranked by study type: (I) systematic review, meta-analyses of randomized controlled trials; (II) randomized controlled studies; (III) nonrandomized intervention studies; (IV) observational studies; (V) nonexperimental studies; and (VI) expert opinion [20]. Qualitative articles were ranked on a four-level system according to their level of good evidence-for-practice: (1) generalizable studies; (2) conceptual studies; (3) descriptive studies; (4) single case study [21].

reassurance and support was the strongest motivator to participants.

Aquatherapy has been especially beneficial in patients with MS due to the reduction in the risk of falls in water [26]. Four RCTs examined the use of aquatherapy in MS. Mori et al., examined the effect of exercise therapy combined with transcranial magnetic stimulation (TMS) on motor disability in MS, and showed that exercise therapy plus TMS showed greater and more consistent improvements over TMS 
Table 2

Outcomes measured in included studies

\begin{tabular}{|c|c|c|c|c|c|c|c|c|}
\hline \multirow[b]{2}{*}{ Study } & \multicolumn{8}{|c|}{ Outcomes measured } \\
\hline & 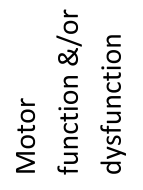 & $\begin{array}{l}\frac{2}{+0} \\
\frac{0}{0} \\
\frac{\pi}{5} \\
\frac{0}{E} \\
\frac{1}{4}\end{array}$ & $\vec{\circ}$ & 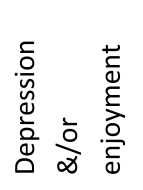 & 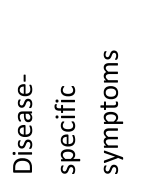 & 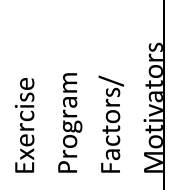 & 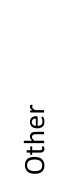 & \\
\hline Vivas et al. [23] & $\bullet$ & $\bullet$ & & & $\bullet$ & & & \\
\hline Ayan and Cancela [24] & $\bullet$ & & $\bullet$ & & $\bullet$ & & & \\
\hline Giladi [25] & $\bullet$ & $\bullet$ & & & & & & \\
\hline $\begin{array}{l}\text { Crizzle and Newhouse } \\
\text { [26] }\end{array}$ & & & & & & $\bullet$ & & \\
\hline Mori et al. [27] & $\bullet$ & & $\bullet$ & & $\bullet$ & & & \\
\hline $\begin{array}{l}\text { Castro-Sanchez et al. } \\
\text { [28] }\end{array}$ & & & & $\bullet$ & $\bullet$ & & & \\
\hline Kargarfard et al. [29] & & & $\bullet$ & & & & r & $\bullet$ \\
\hline Bansi et al. [30] & & & & & & & r & $\bullet$ \\
\hline Salem et al. [31] & $\bullet$ & & & $\bullet$ & & $\bullet$ & & \\
\hline Coco et al. [32] & $\bullet$ & & & & & & . & $\bullet$ \\
\hline Gehlsen et al. [33] & & $\bullet$ & & & & & & \\
\hline Correia de Sa et al. [34] & & & & & $\bullet$ & & & \\
\hline Beer et al. [35] & $\bullet$ & & & & $\bullet$ & & & \\
\hline Peterson \& Bell [36] & $\bullet$ & $\bullet$ & & & & & & \\
\hline Woods [37] & $\bullet$ & $\bullet$ & & & & & & \\
\hline Pappalardo et al. [38] & & & & & $\bullet$ & & & \\
\hline Henze et al. [39] & & & & & $\bullet$ & & & \\
\hline Peterson [40] & $\bullet$ & $\bullet$ & & & & & & \\
\hline Broach and Dattilo [41] & $\bullet$ & $\bullet$ & & & & & r & $\bullet$ \\
\hline Broach and Dattilo [42] & $\bullet$ & & & & & & & \\
\hline Broach et al. [43] & & & & $\bullet$ & & & & \\
\hline Apel et al. [44] & & & & & & & r & $\bullet$ \\
\hline Apel et al. [45] & & & & & & & 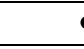 & - \\
\hline Fawcett et al. [46] & & & & & & & r & $\bullet$ \\
\hline Lewis [47] & & & & $\bullet$ & $\bullet$ & & & \\
\hline O'Connell [48] & $\bullet$ & & & & & $\bullet$ & & \\
\hline Veenstra et al. [49] & & & $\bullet$ & & & $\bullet$ & & \\
\hline Andersen et al. [50] & & & & & $\bullet$ & & & \\
\hline $\begin{array}{l}\text { Bedlack and Aggarwal } \\
\text { [51] }\end{array}$ & & & & & $\bullet$ & & & \\
\hline Johnson [52] & $\bullet$ & & & & & & . & $\bullet$ \\
\hline Sheaff [18] & & & & & $\bullet$ & & & \\
\hline
\end{tabular}

Dark grey background indicates improvement from an aquatherapy intervention in measured variables, light gray background indicates observed or self-reported improvement where measured variables are not available.

alone [27]. Castro-Sanchez et al., assessed the use of hydrotherapy for pain in MS [28], and found that the hydrotherapy resulted in significant improvements in pain intensity, spasm, fatigue, disability, and autonomy. Kargarfard et al. used an aquatherapy program to evaluate fatigue and health-related quality of life in MS [29]. Results showed improvements in the exercise group but no change in a control group. Bansi et al. used land versus water cycling as an intervention in MS and compared serum markers between groups 
[30]. The authors found increased serum brain-derived neurotrophic factor levels in the water-cycling group, while no change was seen in the land group.

Two observational studies followed participants with MS through aquatherapy programs and found the interventions to be feasible, safe, and associated with significant improvements on various motor scales $[31,32]$. A third observational study examined the impact of aquatherapy on gait in MS, however none of the specific parameters analyzed showed significant improvements [33]. Multiple reviews have looked at aquatherapy use in MS, and have suggested that aquatherapy may be beneficial for symptomatic treatment of MS, especially due to its positive effects on spasticity [34-37]. There is limited support (in the form of small case studies) for the use of aquatherapy to improve fitness variables such as walking endurance, upper extremity strength, or muscular endurance, however these variables need to be assessed quantitatively in randomized groups before conclusions can be drawn $[36,37]$. Expert opinion papers suggest the use of aquatherapy as treatment for spasticity, arguing that therapy may decrease spasticity and the need for medication use [38, 39]. A single case report suggests that warm water exercise may be used to "promote muscular relaxation, decrease pain and increase range of motion" in MS [40, p. 1051].

Three retrospective survey studies assessed different aspects of aquatherapy in MS [41, 43]. Motor function appeared to improve, and all participants either maintained or improved strength in these programs and reported that these programs were enjoyable [41, 43]. Multiple surveys have been conducted to better understand what proportions of the MS population seek complementary medical therapy, and find that only a small percentage $(1.5 \%)$ use hydrotherapy [44-46]. Lewis [47] and O'Connell [48] both describe aquatherapy programs and their potential benefits in MS, however discrete variables are not discussed. Veenstra et al. found that healthy adults and people living with MS participate in water exercise programs for similar reasons, and that adults with MS who participated in aquatherapy had greater life satisfaction than those with MS who did not participate in aquatherapy [49].

In a review document by the European Federation of Neurological Societies task force, Andersen et al., suggest hydrotherapy for symptomatic management of cramps and spasticity in ALS [50]. There are no controlled studies in ALS and this recommendation is supported by an expert opinion paper and a single case report [51, 52].
For HD, one study described a once-weekly aquatherapy program for a 50 year-old male who was in the later stages of disease. Gentle exercises in warm water were suggested to be beneficial due to the observed reduction in choreic movements during and for a time following the aquatherapy sessions, however specific outcomes were not measured [18].

\section{SUMMARY AND CONCLUSIONS}

The current evidence to support the use of aquatherapy in HD, PD, MS, and ALS is inconclusive when generalized across these four disorders, however there is some experimental evidence supporting the use of aquatherapy in PD and in MS. Studies of aquatherapy in PD and MS include RCTs and larger trials, which provide stronger evidence supporting a benefit for exercise therapy in these conditions. Studies in PD comparing land-based to water-based exercise programs demonstrated better results for water-based programs [23, 24]. Large studies in MS showed evidence for benefit of aquatherapy on pain, fatigue and HRQOL [27-30]. Subject characteristics (such as age, gender, and stage of disease) were well described, therefore these trials could be replicated. The literature would benefit from replication of these studies to determine if implementation of aquatherapy programs in populations with PD or MS is warranted. Studies in HD [18] and ALS [50-52] were too few and of too poor methodological rigor to draw any clear conclusions for or against the use of aquatherapy in these populations. No RCTs have been reported in either population, only reviews and case reports exist describing any sort of aquatherapy intervention. Additionally, the populations and methods of these studies were not described specifically enough to be replicable in future research. There is a need for larger and more robust experimental studies regarding the use of aquatherapy in populations of HD and ALS.

A shortcoming of this field of study is the wide variety of assessment tools used in different studies. We recommend standardized methods of measurement be developed and used so that results are comparable between studies. Valid and reliable measurement tools include standardized QOL scales, the Unified Parkinson's Disease Rating Scale (UPDRS) for PD, the Unified Huntington's Disease Rating Scale (UHDRS) for HD, etcetera. These scales assess multiple disease domains such as, motor function, cognitive ability, functional ability, and behavior, and their use would 
help standardize the clinical impact of aquatherapy on disease progression in these disorders.

Aquatherapy is safe and feasible in PD and MS, and has been shown to help pain and spasticity in some RCTs, but it should be evaluated more rigorously for efficacy in these diseases, as well as in HD and ALS. Large well-controlled trials of aquatherapy in HD and other neurodegenerative diseases need to be conducted to provide a basis for evidence-based clinical practice.

\section{ACKNOWLEDGMENTS}

Both authors provided concept/idea/research design. Ms Plecash provided data collection, writing, and review of manuscript before submission. Dr Leavitt provided writing and review of manuscript before submission. Funding support for this study was provided by a UBC Summer Research Student Grant, CFRI and The University of British Columbia.

\section{CONFLICT OF INTEREST}

The authors declare that they have no conflict of interest.

\section{REFERENCES}

[1] Becker B. Aquatic therapy: Scientific foundations and clinical rehabilitation applications. Phys Med Rehabil. 2009;1(9):859-72.

[2] Bartels EM, Lund H, Hagen KB, Dagfinrud H, Christensen R, Danneskiold-Samsøe B. Aquatic exercise for the treatment of knee and hip osteoarthritis. Cochrane Database Syst Rev. 2007;4:CD005523

[3] Sato D, Kaneda K, Wakabayashi H, Nomura T. Comparison two-year effects of once-weekly and twice weekly water exercise on health-related quality of life of community-dwelling frail elderly people at a day-service facility. Disabil Rehabil. 2009;31(2):84-93.

[4] Sato D, Kaneda K, Wakabayashi H, Nomura T. Comparison of two-year effects of once and twice weekly water exercise on health-related quality of life of community-dwelling frail elderly people at a day-service facility. Arch Gerontol Geriatr. 2009;49(1):123-8.

[5] Mehrholz J, Kugler J, Pohl M. Water-based exercises for improving activities of daily living after stroke (Review). Cochrane Database Syst Rev. 2011;1:CD008186.

[6] Chu KS, Eng JJ, Dawson AS, Harris JE, Ozkaplan A, Gylfadottir S. Water-based exercise for cardiovascular fitness in people with chronic stroke: A randomized controlled trial. Arch Phys Med Rehabil. 2004;85:870-4.

[7] Taunton JE, Rhodes EC, Wolski LA, Donelly M, Warren J, Elliot J, McFarlane L, Leslie J, Mitchell J, Lauridsen B. Effect of land-based and water-based fitness programs on the cardiovascular fitness, strength and flexibility of women aged 65-75 years. Gerontology. 1996;42(4):204-10.
[8] Gusella JF, MacDonald ME, Ambrose CM, Duyao MP. Molecular genetics of Huntington's disease. Arch Neurol. 1993;50(11):1157-63.

[9] Huntinton's Disease Collaborative Research Group. A novel gene containing a trinucleotide repeat that is expanded and unstable on Huntington's disease chromosomes. Cell. 1993;72:971-83.

[10] EHDN Physiotherapy Working Group. Physiotherapy guidance document. 2009:3-178.

[11] Bilney B, Morris ME, Perry A. Effectiveness of physiotherapy, occupational therapy, and speech pathology for people with Huntington's disease: A systematic review. Neurorehabil Neural Repair. 2003;17:12-24.

[12] Sheaff F. Hydrotherapy in Huntington's disease. Nursing Times. 1990;86:46-9.

[13] Van Dellen A, Cordery P, Spires T, Blakemore C, Hannan A. Wheel running from a juvenile age delays onset of specific motor deficits but does not alter protein aggregate density in a mouse model of Huntington's disease. BMC Neurosci. 2008;9(1):34-45.

[14] Harrison DJ, Busse M, Openshaw R, Rosser AE, Dunnett SB, Brooks SP. Exercise attenuates neuropathology and has greater benefit on cognitive than motor deficits in the R6/1 Huntington's disease mouse model. Exp Neurol. 2013;248:457-69.

[15] Konerth M, Childers J. Exercise: A possible adjunct therapy to alleviate early Parkinson disease. JAAPA. 2013;26(4):30-3.

[16] Alonso-Frech F, Sanahuja JJ, Rodriguez AM. Exercise and physical therapy in early management of Parkinson disease. Neurologist. 2011;17(6s):s47-s53.

[17] Romberg A, Virtanen A, Ruutiainen J, Aunola S, Karpi SL, Vaara M, Surakka J, Pohjolainen T, Seppanen A. Effects of a 6-month exercise program on patients with multiple sclerosis: A randomized study. Neurology. 2004;63:2034-8.

[18] White LC, McCoy SC, Castellano V, Gutierrez G, Stevens JE, Walter GA, Vandenborne K. Resistance training improves strength and functional capacity in persons with multiple sclerosis. Mult Scler. 2004;10:668-74.

[19] Chen A, Montes J, Mitsumoto H. The role of exercise in amyotrophic lateral sclerosis. Phys Med Rehabil Clin N Am. 2008; 19:545-57.

[20] United States Department of Health and Human Services. Agency for Health Care Policy and Research. Acute pain management: Operative or medical procedures and trauma. Rockville, MD: AHCPR; 1993:107. (Clinical practice guideline No 1, AHCPR publication No 92-0023.)

[21] Daly J, Willis K, Small R, Green J, Welch N, Kealy M, Hughes E. A hierarchy of evidence for assessing qualitative health research. J Clin Epidemiol. 2007;60:43-9.

[22] Vivas J, Arias P, Cudeiro J. Aquatic therapy versus conventional land-based therapy for Parkinson's Disease: An open-label pilot study. Arch Phys Med Rehabil. 2011;92:1202-10.

[23] Ayan C, Cancela J. Feasibility of 2 different water-based exercise training programs in patients with Parkinson's Disease: A pilot study. Arch Phys Med Rehabil. 2012;93:1709-14.

[24] Giladi N. Mobility and exercise in movement disorders. Parkinsonism Relat Disord. 2009;15S3:S46-8.

[25] Crizzle AM, Newhouse IJ. Themes associated with exercise adherence in persons with Parkinson's Disease: A qualitative study. Occup Ther Health Care. 2012;26(2-3):174-86.

[26] Broach E, Dattilo J. The effect of aquatic therapy on strength of adults with multiple sclerosis. Ther Recreation J. 2003;37:224-39.

[27] Mori F, Ljoka C, Magni E, Codeca C, Kusayanagi H, Monteleone F, Sancesario A, Bernardi G, Koch G, Foti C, 
Centonze D. Transcranial magnetic stimulation primes the effects of exercise therapy in multiple sclerosis. J Neurol. 2011;258:1281-7.

[28] Castro-Sanchez AM, Mataran-Penarrocha GA, Lara-Palomo I, Saavedra-Hernandez M, Arroyo-Morales M, MorenoLorenzo C. Hydrotherapy for the treatment of pain in people with Multiple Sclerosis: A randomized controlled trial. Evid Based Complement Alternat Med. 2012;2012:473963.

[29] Kargarfard M, Etemadifar M, Baker P, Mehrabi M, Hayatbakhsh R. Effect of aquatic exercise training on fatigue and health-related quality of life in patients with Multiple Sclerosis. Arch Phys Med Rehabil. 2012;93:1701-8.

[30] Bansi J, Bloch W, Gamper U, Kesselring J. Training in MS: Influence of two different endurance training protocols (aquatic versus overland) on cytokine and neurotrophin concentrations during three week randomized controlled trial. Mult Scler J. 2012;19(5):613-21.

[31] Salem Y, Hiller Scott A, Karpatkin H, Concert G, Haller L, Kaminsky E, Weisbrot R, Spatz E. Community-based group aquatic programme for individuals with Multiple Sclerosis: A pilot study. Disabil Rehabil. 2011;33(9):720-8.

[32] Coco M, Maugeri A, Perciavalle V. Effects induced by swim on a patient with Multiple Sclerosis: Case report. Acta Medica Mediterranea. 2006;21:85-92

[33] Gehlsen G, Beekman K, Assmann N. Gait characteristics in multiple sclerosis: Progressive changes and effects of exercise on parameters. Arch Phys Med Rehabil. 1986;6:536-9.

[34] Correia de Sa JC, Airas L, Bartholome E, Grigoriadis N, Mattle H, Oreja-Guevara C, O'Riordan J, Sellebjerg F, Stankoff B, Vass K, Walczak A, Wiendl H, Kieseier BC. Symptomatic therapy in multiple sclerosis: A review for a multimodal approach in clinical practice. Ther Adv Neurol Disord. 2011;4(3):139-68.

[35] Beer S, Khan F, Kesselring J. Rehabilitation interventions in multiple sclerosis: An overview. J Neurol. 2012;259:19942008.

[36] Peterson JL, Bell GW. Aquatic exercise for individuals with multiple sclerosis. Clin Kinesiol. 1995;49:69-71.

[37] Woods DA. Aquatic exercise programs for patients with multiple sclerosis. Clin Kinesiol. 1992;46:14-20.

[38] Pappalardo A, Castiglione A, Restivo DA, Calabrese A, Patti F. Non-pharmacologic interventions for spasticity associated with Multiple Sclerosis. Neurol Sci. 2006;27:S316-9.
[39] Henze T, Rieckmann P, Toyka KV. Symptomatic treatment of multiple sclerosis. Eur Neurol. 2006;56:78-105.

[40] Peterson C. Exercise in $94^{\circ} \mathrm{F}$ water for a patient with multiple sclerosis. Phys Ther. 2001;81:1049-58.

[41] Broach E, Dattilo J. Effects of aquatic therapy on adults with multiple sclerosis. Ther Recreation J. 2001;35:141-54.

[42] Broach E, Dattilo J. The effect of aquatic therapy on strength of adults with multiple sclerosis. Ther Recreation J. 2003;37:224-39.

[43] Broach E, Dattilo J, McKenney A. Effects of aquatic therapy on perceived fun or enjoyment experiences of participants with multiple sclerosis. Ther Recreation J. 2007;41:179-200.

[44] Apel A, Greim B, Konig N, Zettl UK. Frequency of current utilisation of complementary and alternative medicine by patients with multiple sclerosis. J Neurol. 2006;253:1331-6.

[45] Apel A, Greim B, Zettl UK. How frequently do patients with multiple sclerosis use complementary and alternative medicine? Complement Ther Med. 2005;13:258-63.

[46] Fawcett J, Sidney JS, Hanson MJS, Riley-Lawless K. Use of alternative health therapies by people with Multiple Sclerosis: An exploratory study. Holistic Nurse Pract. 1994;8(2):36-42.

[47] Lewis SM. Therapeutic swimming: A different kind of nursing. J Nurs Educ. 1985;24:125

[48] O'Connell R. Exercise therapy in multiple sclerosis. Physiother Ireland. 2005;26(1):23-6.

[49] Veenstra J, Brasile F, Stewart M. Perceived benefits of aquatic therapy for multiple sclerosis participants. Am J Recreat Ther. 2003;2(1):33-48.

[50] The EFNS Task Force on Diagnosis and Management of Amyotrophic Lateral Sclerosis: Andersen PM, Abrahams S, Borasio GD, de Carvalho M, Chio A, Van Damme P, Hardiman O, Kollewe K, Morrison KE, Petri S, Pradat P-F, Silani V, Tomik B, Wasner M, Weber M. EFNS guidelines on the Clinical management of Amyotrophic Lateral Sclerosis (MALS) - revised report of an EFNS task force. Eur J Neurol. 2012;19:360-75.

[51] Bedlack RS, Aggarwal S. ALS update: Signs of progress, reasons for hope. Continuum Lifelong Learning Neurol. 2009; 15:83-110.

[52] Johnson CR. Aquatic therapy for an ALS patient. Am J Occup Ther. 1988;42:115-20. 